Article

\title{
On Approaching Relevant Cost-Effective Sustainable Maintenance of Mineral Oil-Filled Electrical Transformers
}

\author{
Ramsey Jadim ${ }^{1, * \mathbb{D}}$, Mirka Kans ${ }^{1} \mathbb{D}$, Jesko Schulte ${ }^{2} \mathbb{D}$, Mohammed Alhattab ${ }^{3} \mathbb{D}$, May $^{\text {Alhendi }}{ }^{3}(\mathbb{D}$ \\ and Ali Bushehry ${ }^{3}$ iD
}

1 Department of Mechanical Engineering, Faculty of Technology, Linnaeus University, 35195 Växjö, Sweden; mirka.kans@lnu.se

2 Department of Strategic Sustainable Development, Blekinge Institute of Technology, 37179 Karlskrona, Sweden; jesko.schulte@bth.se

3 Primary Substation Maintenance Department, Ministry of Electricity and Water, Safat 13001, Kuwait; mohammed.alhattab@mew.gov.kw (M.A.); may.alhendi@mew.gov.kw (M.A.); ali.hussain@mew.gov.kw (A.B.)

* Correspondence: ramsey.jadim@lnu.se

check for

updates

Citation: Jadim, R.; Kans, M.; Schulte, J.; Alhattab, M.; Alhendi, M.; Bushehry, A. On Approaching Relevant Cost-Effective Sustainable Maintenance of Mineral Oil-Filled Electrical Transformers. Energies 2021, 14, 3670. https://doi.org/10.3390/ en14123670

Academic Editors: T M Indra Mahlia and Islam Md Rizwanul Fattah

Received: 20 May 2021

Accepted: 18 June 2021

Published: 20 June 2021

Publisher's Note: MDPI stays neutral with regard to jurisdictional claims in published maps and institutional affiliations.

Copyright: (c) 2021 by the authors. Licensee MDPI, Basel, Switzerland. This article is an open access article distributed under the terms and conditions of the Creative Commons Attribution (CC BY) license (https:/ / creativecommons.org/licenses/by/ $4.0 /)$.

\begin{abstract}
Fire and explosion accidents of oil-filled electrical transformers are leading to negative impacts, not only on the delivery of energy, but also on workplace health and safety as well as the surrounding environment. Such accidents are still being reported, regardless of applying the regular maintenance strategy in the power plants. The purpose of this paper is to integrate a sustainability perspective into the maintenance strategy. The problem addressed is: how can we approach the relevant cost-effective sustainable maintenance for oil-filled electrical transformers? For this purpose, an empirical study in a power plant in Kuwait was introduced. The first stage was to carry out a sustainability assessment using the ABCD procedure. In this procedure, gaps to approach sustainability were identified and actions prioritized to close these gaps were demonstrated. Applying this procedure yielded an early fault diagnosis (EFD) model for achieving cost-effective sustainable maintenance using a fault trend chart based on a novel numerical method. Implementing this model resulted in an extension of the lifetime of transformers with suspected failure propagation, leading to a deferral of the replacement investment costs. The principal conclusion of this paper is the importance of viewing the maintenance strategy of transformers from a strategic sustainability perspective, in order to approach relevant cost-effective sustainable maintenance.
\end{abstract}

Keywords: maintenance strategy; sustainable maintenance; $A B C D$ procedure; strategic sustainable development; transformer failures

\section{Introduction}

The basic components of an oil-filled electrical transformer are copper windings and an iron core. The windings contain copper coil turns bundled together and wrapped with insulating paper. These components are entirely immersed in a mineral insulating oil in the transformer tank [1]. Overheating of the insulating oil in-service can occur due to increased current load, oxidation, and corrosion deposits on windings, or unexpected electrical and mechanical faults resulting in the formation of partial discharge (corona) and arcing phenomena, which in turn can generate flammable gases. The energy in these phenomena can be very high and develop temperatures in hundreds of degrees, though for a short time, causing fire and explosion accidents [2-5]. The transformer fires that contain several tons of mineral insulating oil can not only impact on the delivery of energy, but also on workplace health and the surrounding environment [6,7]. In [8], statistical data analysis of the failure rate of European substation transformers between 2000 and 2010 showed that around $9.5 \%$ of the total failures caused fire accidents and 3.3\% caused explosion accidents. Another source of failure rates from 2015 [9] showed a significant increase in fire and explosion accidents in USA. These accidents occurred regardless of using the regular maintenance strategy during the transformer's useful life [2,10]. 
The common regular maintenance strategy used for high voltage substation power transformers is condition-based maintenance (CBM) [3,11] which is defined according to EN 13306:2017 [12] as "preventive maintenance, which includes assessment of physical conditions, analysis and the possible ensuing maintenance actions". Oil analysis technology is commonly used in the condition monitoring $(\mathrm{CM})$ parameters to detect faults, such as partial discharge, arcing, oxidation, and corrosion [2,13-15]. Fault detection is based on the concentration value level of the measurable variables, such as hydrogen gas, acetylene gas, acidity, hydrogen sulfide gas, toluene, and more, related to the standard caution limit (the maximum value that indicates fault incidence). The corrective action is carried out once the measured value of a measurable variable exceeds its caution limit [13-17]. Onsite electrical testing technology is also used in the maintenance strategy to identify the type and location of the fault. However, this technology is usually recommended at the transformer shutdown time for scheduled maintenance or when a fault is suspected $[3,18]$. Assessment of the transformer's condition, based on CM parameters, is a crucial key in the CBM. In this context, several mathematical models are utilized in modelling the deterioration status in order to assess the overall condition of transformers $[11,19,20]$. The drawbacks of these models are modelling the deterioration with a single path without considering the complexity of the deterioration in transformers [21], and the assessment of overall condition without providing information about the root cause of the fault [20].

Sustainable maintenance of transformers is considered a new challenge that requires an understanding of the process of sustainable development and the integration between social and environmental aspects $[11,22,23]$. The vital objectives of sustainable maintenance are extending the lifetime of the transformers and reducing the negative impacts in a way that contributes to the organization's own competitiveness [24]. Sustainable maintenance is defined according to [22] as "proactive maintenance operations striving for providing balance in social, environmental, and financial dimensions". Nowadays, investigations spotlight three technical methods for achieving sustainable maintenance. The first method [25], is selecting energy-efficient green transformers from manufacturers that perform best with sustainability aspects. The concept of "green" according to [26] is related to a consideration of the environmental aspect as well as the economic benefit. An example of this method is provided by qualified raw resources such as amorphous materials used in the core design, yielding a core with higher hardness compared to current common iron core (silicon steel laminations), resulting in reduced energy loss and greenhouse gas emissions [25]. The main shortcoming of this method is its availability only for the newly manufactured transformers. The second method [27-29] is replacing the mineral insulating oil with natural ester oil. The strength in using natural ester oil is the excellent specifications, such as higher cooling efficiency, lower inflammation risk due to high flash point value, and lower toxicity than mineral oil. The disadvantages of this oil are the low electrical resistivity, which reduces the insulation capability of the oil, and the high investment costs comparing with mineral oil [28]. The last method [30] is the waste oil recycle process to remove the hazard contamination. One of the vital techniques in this process is using the reduction procedure to remove the toxic chemical, such as polychlorinated biphenyl (PCB) from oil waste, which has negative impacts on human and environmental health [31]. In general, the most critical challenge for achieving sustainable maintenance is the investment costs of these available technical methods and the return on investment $[25,27,30]$. Therefore, it is crucial and necessary to establish a relevant sustainable maintenance with regard to minimized costs, i.e., relevant cost-effective sustainable maintenance. The purpose of this paper is to integrate sustainability perspective into the maintenance strategy.

Sustainability assessment in many organizations is still unclear for stakeholders [22,24]. The main reason for this challenge is the complications of carrying out the assessment due to the lack of a well-organized procedure and lack of competence in the integration of sustainability in the maintenance strategy. However, the sustainability assessment can be addressed by utilizing ABCD procedure of the Framework for Strategic Sustainable 
Development (FSSD) [32-34]. The outcome of applying this procedure in a power plant was creating a model for early fault diagnosis to achieve the prioritized action for improving the maintenance strategy toward sustainability.

\section{Methods and Materials}

\subsection{Methodological Approach}

An empirical study was applied in this study to explore how a strategic sustainability perspective could be integrated into the maintenance strategy of transformers in order to approach relevant cost-effective sustainable maintenance. According to [35], an empirical study design should include five elements. The first element is the formulation of relevant questions related to the problem, which can be used in the first interview with the organization team. The second element is study propositions to be examined in the research. The third element is the identification of the problem to be studied. In this step, the problem should be defined and bounded. These three elements can help in identifying the data to be collected. The fourth element is linking the collected data to the study propositions. The last is establishing criteria for interpreting the findings. The last two elements elucidate the suggested process after the data have been collected. These elements are handled in this empirical study by using the $\mathrm{ABCD}$ procedure structure to assess sustainability. Therefore, the $A B C D$ procedure acts both as a structure for achieving the study design and as a theoretical framework to be tested for its applicability in the context of maintenance strategy development.

\subsection{The $A B C D$ Procedure}

A long-term strategic perspective is crucial when working with sustainability to ensure that actions lead in the right direction towards full sustainability and contribute to the own organization's competitiveness. In order to be strategic, it is necessary to know the desired vision of success. This comes with the challenge of defining sustainability in a way that is neither too broad, not providing any guidance in practice, nor too specific, making it difficult for people to agree and risking becoming obsolete in the face of, for example, new technology advances. Within the Framework for Strategic Sustainable Development (FSSD), the following principle-based definition of sustainability is used: In a sustainable society, nature is not subject to systematically increasing (1) concentrations extracted from the Earth's crust, (2) concentrations of substances produced by society, (3) degradation by physical means; and people are not subject to structural obstacles to (4) health, (5) influence, (6) competence, (7) impartiality, and (8) meaning-making [33,34,36]. These eight principles represent the root-causes of unsustainability, up-stream in cause-and-effect chains. Thereby, the myriad unsustainability-related impacts in social and ecological systems, such as climate change, biodiversity loss, ozone depletion, discrimination, etc., can be related to a few comprehensive mechanisms of destruction. These eight principles can be used as boundary conditions for the re-design of socio-technical systems. They can be used to create that vision, which is necessary to be able to be strategic. This provides the basis for backcasting, i.e., starting the planning process with the end in mind, asking what is necessary to happen in order to reach the vision over time. Thereby, the direction of change can be anticipated, enabling decision-making that makes sure to be on the right track and giving benefits to the organization, e.g., by being ahead of legislation or meeting new customer demands [37]. The funnel metaphor of the FSSD can be used to understand the sustainability challenge and the self-benefit of strategic sustainability thinking based on backcasting from a vision framed by the eight sustainability principles $[34,36,38]$ (see Figure 1). 


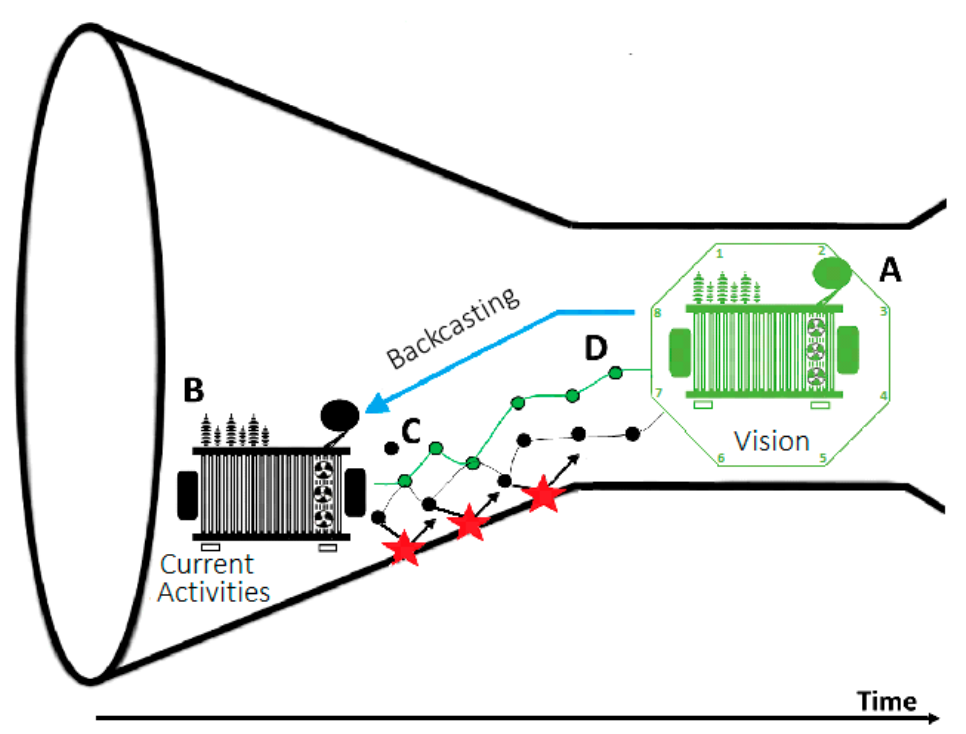

Figure 1. Funnel metaphor for transformers and the ABCD procedure for strategic sustainable development. The violations of the sustainability principles are represented here as red stars, which are hitting the funnel wall. These violations should be evaluated to identify the hotspots of sustainability impact.

The decreasing cross-section of the funnel represents the systematic degradation of the social and ecological systems. Over time, a situation must be achieved where this is no longer the case, and the funnel turns into a cylinder-this represents a sustainable state. However, society is currently moving towards the funnel walls, which represents a collapse of the social and ecological systems. This unsustainable development comes with important dynamics from a business perspective. The closer society comes to the funnel walls, the greater the need for sustainable solutions and to stop unsustainable practices. Therefore, there will be increasing business opportunities for companies that can contribute towards developing a sustainable path, while there will be increasing threats for companies that enforce unsustainable development. Such threats and opportunities, i.e., risks, can be related to, for example, legislative change, brand and reputation, shifting customer needs, raw material and waste costs, the ability to attract and retain talented employees, and more [37]. An organization must identify solutions that can work as flexible platforms on the way towards the sustainable vision and that help to exploit business opportunities and avoid threats [39].

To operationalize this strategic sustainability thinking, the FSSD includes the ABCD procedure. Step A includes setting up a shared understanding of the sustainability challenge and defining the overall vision within the restrictions of the sustainability principles. In this step, the organization must take a long-term perspective and think of an ideal success vision. Besides the sustainability principles, there are no other constraints such as the feasibility from today's perspective. The vision created in this step provides the basis for backcasting. In step B, an assessment of the organization's current reality and activities are carried out and analyzed through the lens of the proposed vision. Thereby, hots-spots of sustainability impact are identified, and a baseline is created. In step C, possible actions are identified and listed to close the gaps between the vision defined in step A and the current reality that was analyzed in the step B. In step D, strategic guidelines are applied to analyze the possible actions in the step $C$ and select the prioritized ones to be utilized in the organization's plan of moving to sustainability. According to the basic strategy guidelines of the FSSD, the prioritized actions should be flexible platforms for future steps and achieve a balance between the rate of improvement toward the sustainable vision and return on investment $[33,34,36]$. The organizations need to ensure that the return on investment of applying the prioritized actions toward sustainability is satisfactory to continue the 
process of moving toward sustainability. However, when the cost of actions is very high, it is recommended to wait for more studies and investigations in order to find appropriate economic solutions. The actions that can be easily implemented with a good return on investment should be started first to set up a concrete structure for the future process for the other actions [33,34]. The ABCD procedure has been applied in various contexts to support strategic planning for sustainability, including in the context of sustainable product development [32].

\subsection{Empirical Study Design}

The ABCD procedure was applied in the Primary Substation Maintenance Department (PSMD) power plant, an organization of the Ministry of Electricity and Water in Kuwait State. The PSMD power plant is responsible for moving toward sustainability, primarily to prevent fire and explosion accidents of transformers, which recently increased. According to statistical data from PSMD power plant, around 1.5\% of 3950 transformers were reported as out of service due to fire and explosion accidents during the last two decades, regardless of applying the regular maintenance strategy. In addition, there is also a growing problem of oil waste due to the replacement of many old and scraped transformers with new ones. The PSMD power plant was selected among others in this study due to the availability of good historical data of a massive quantity of transformers, and the appreciated cooperation of the maintenance team. Two online workshop meetings were organized by the first author with the PSMD team from maintenance, safety, and economic departments. The first workshop took around three hours, where relevant questions were addressed to the PSMD team. The main questions discussed the vision, current condition monitoring practices, actions need for sustainable maintenance, and current sustainability challenges. The problem of the increasing rate of fire and explosion accidents was also discussed. The second workshop took around two hours, where the problem was defined and bounded, and the propositions were studied. Accordingly, the capability to implement the ABCD procedure to integrate a strategic sustainability perspective in the current maintenance strategy was proposed. Besides, the need for the development of an effective diagnosis model for early fault detection was also proposed. The PSMD team approved to provide access to oil analysis data of 972 nominated oil-filled electrical transformers, with medium and large power rates, from the laboratory's application software in order to evaluate the transformers' condition and study the current activities from a sustainability perspective. The outcome of the gathered data of the oil analysis was analyzed and categorized according to the fault type (see Figure 2). The importance of the categorized data is identifying the fault types and defining the category that can be utilized in the ABCD procedure.

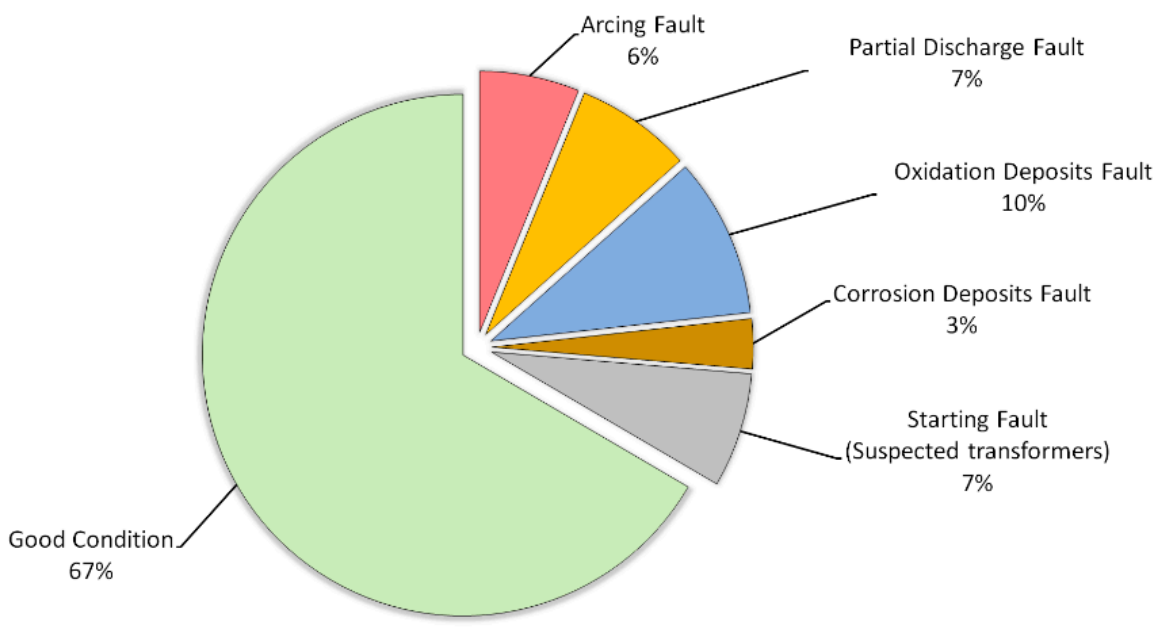

Figure 2. Fault type mode analysis of 972 transformers of the PSMD power plant. 
The category of "Arcing Fault" is at $6 \%$ of the fault mode. The arcing fault can be indicated by detecting a high concentration value above the caution limit of the two gases, hydrogen and acetylene. This arcing can generate extremely high temperatures over $700{ }^{\circ} \mathrm{C}$, though for a short time, in the oil, leading to fire accidents $[4,13,16]$. The category "Partial Discharge Fault" is at $7 \%$ of the fault mode. Partial discharge can be indicated by detecting a high concentration value above the caution limit of the hydrogen gas in the oil. This fault can occur at any temperature over $200^{\circ} \mathrm{C}[4,13,16]$. The category of "Oxidation Deposits Fault" is at $10 \%$, the most dominant fault mode. Oxidation products such as acidity may convert to ester and thereafter form sludge deposits on the transformers' windings. This fault can be indicated by detecting a high concentration value above the caution limit of the acidity in the oil $[5,15]$. The category of "Corrosion Deposits Fault" is at $3 \%$ of the fault mode. The corrosion deposits are in the form of copper sulfide on the windings of the transformers. This fault can be indicated by detecting a high concentration value above the caution limit of the hydrogen sulfide gas and toluene compound in the oil [2]. The category "Starting Fault" is at 7\% of the fault mode. This category represents the transformers with suspected failure propagation, that have a fault in progress and need corrective action. The investigation in this study focused on the "Starting Fault" category to apply a model of early fault diagnosis in order to follow up the fault before progression to a risky level. The last category "Good Condition" represents the transformers which have not any fault's indication.

\section{Results}

In this section, the results of applying the $\mathrm{ABCD}$ procedure on the transformers of the PSMD power plant are presented, as well as a model for early fault diagnosis, which was identified as a prioritized action.

\subsection{ABCD Procedure for PSMD Power Plant}

As seen from the fault type mode in Figure 2, the percentage of the total fault incidences was around $26 \%$ of the addressed transformers. These faults have already occurred and need proper corrective actions to avoid further progress. However, the recommended corrective actions for these faults are demonstrated in the discussion section. The category that needs to be further investigated from a sustainability perspective is "Starting Fault", to detect faults in the initial stage and find solutions to avoid transformer failures.

\subsubsection{Step A: Building a Shared Understanding and Vision}

The main vision of the PSMD power plant is to provide sustainable power for customers in the future with regard to minimized costs and implied integration between maintenance and sustainability aspects; social, environmental, and economic. The other visions are preventing transformers failures and catastrophic accidents, extending the lifetime of the transformers, and finding a solution to the hazardous oil waste.

\subsubsection{Step B: Assessing the Current Reality}

In this step, the current activities in the maintenance of transformers of the PSMD power plant were investigated. Furthermore, the violations of the sustainability principles were evaluated to identify hotspots of sustainability impact. In this study, oil analysis technology is exclusively used in the condition monitoring (CM) parameters. The electrical testing was excluded in this study due to the shortcoming in this technology to detect a fault in the initial stage $[3,18]$. Measurable variables of oil analysis are demonstrated in Table 1. 
Table 1. Measurable variables of oil analysis related to fault type used in the PSMD power plant.

\begin{tabular}{ccc}
\hline Measurable Variable (Oil Analysis) & Fault Type & Standard Method \\
\hline Hydrogen \& Acetylene Gases & Arcing & IEC 60567 [40] \\
Hydrogen Gas & Partial Discharge & IEC 60567 [40] \\
Acidity & Oxidation Deposits & IEC 62021-1 [41] \\
Hydrogen Sulfide Gas \& Toluene & Copper Corrosion Deposits & ASTM D5504 [42] \& D5580 [43] \\
\hline
\end{tabular}

Three significant violations of the sustainability principles were recorded in the PSMD power plant. The first hotspot is the usage of several tons of insulating oil in the transformers. That presents a violation of sustainability principles one and two, since it contributes to systematically increasing concentrations of substances from the Earth's crust (fossil oil) and substances produced by society (chemical products in the oil, which can be persistent and bio-accumulating). The second hotspot is the existence of a huge quantity of oil waste, which can include toxic chemicals used as additives or generated as by-products of chemical reactions in the oil during the transformer's useful life. That can be a violation of sustainability principle two. The third hotspot is the possibility of exposing the workforce or people near the fire and explosion accidents to negative impacts. That can be a violation of sustainability principle four, since it can present a structural obstacle to health.

\subsubsection{Step C: Brainstorming Actions to Close the Gaps}

The main gap in the current maintenance strategy is the shortcoming in detecting faults in the initial stage during the transformers' useful life to prevent failures. In this context, the interpretation and evaluation of the analysis results are currently based on the standard guidelines that recommends corrective action when the measured value of a measurable variable exceeds its caution limit. For example, standard guideline IEC 60422 [15] recommends starting corrective action such as oil regeneration or oil replacement as soon as the acidity value, which is considered the indication key of oxidation deposits on the windings, exceeds its caution limit. However, this corrective action can be no more useful to solve the issue early because the deposits may have already, partially or entirely, formed. Another gap is the lack of the maintenance team's competence in the implementation of sustainable maintenance. Accordingly, a list of possible actions can be indicated to close most of the mentioned gaps. The suggested possible actions in order to comply with the sustainability principles and to approach the vision are:

1. Improving the maintenance strategy for more effectiveness being able to detect early faults and carry out corrective actions at the correct time. Hence, it is necessary to develop an effective fault diagnosis model to provide information that can trigger an alarm for carrying out corrective action before fault incidence, on the other hand, before the measured value of a measurable variable exceeds its caution limit.

2. Providing sustainable maintenance training to enrich the maintenance team of the PSMD power plant with the knowledge of sustainability and improve the company's effectiveness.

3. Recycling waste oil to reduce the impacts of toxic compounds on the environment.

\subsubsection{Step D: Prioritization}

One or more prioritized actions can be selected among the possible actions indicated in step C. Analyzing all these actions shows that the third action received a lower priority due to the requirements of an economic plan to evaluate the return on investment of recycling several tons of waste oils. The first and second actions are the highest priority to the PSMD power plant in order to accomplish the sustainable vision, due to the following strategic guidelines:

- Possibility to apply in today's scenario.

- Flexible platforms for future development if required.

- It can reduce the PSMD power plant misalignments with the sustainability principles. 
- Cost-effective and good return on investment.

For achieving the first prioritized action, a numerical method for early fault detection was developed to define the correct time of carrying out corrective action before the measured value of a measurable variable exceeds its caution limit (see Section 3.2 for details). Furthermore, a model for early fault diagnosis was created based on this numerical method to follow up the fault's progression during the useful life of the transformers, see sub-Section 3.3.

Regarding the second prioritized action, the lack of competence in sustainable maintenance can be a source for improper maintenance. According to a case study in [35], 40\% of the breakdowns of eight Swedish manufactures were due to improper maintenance. It is important for the PSMD power plant to provide training on sustainability for the maintenance team to increase their competence in the sustainable maintenance.

\subsection{Development of Numerical Method}

There are few studies related to the use of mathematical theories to improve the effectiveness of maintenance strategy. An investigation in the study [11] applied Markov prediction model (MPM) to assess transformer condition based on available CM parameters under various pre-determined maintenance repair rates, and to ascertain the corrective action for maintenance, repair, and replacement. The MPM provides a simulation of the asset's deterioration using health index \% (HI) to assess the condition as good, fair, poor, etc. $\mathrm{HI}$ is defined in $[11,19]$ as a method that uses historical condition data in a single measurable index in order to provide a comprehensive assessment of the current state of transformers. In another study [19], a statistical distribution model (SDM) was utilized to predict the $\mathrm{HI}$ of transformers using the data of $\mathrm{CM}$-parameters. The main outcome of applying SDM was establishing a modelling framework for future health index of transformers with even limited historical CM-parameters data. MPM is also applied in an investigation [20] based on CM-parameters to model the future deterioration in the transformers. However, all the mentioned models provided relevant information about the overall current condition status of transformers, and predicted the condition in the future, but none of them integrated a method to detect early faults.

In this study, a novel numerical method was created in order to create a model for early fault diagnosis. The numerical method aims to calculate relative alarm threshold (RAT) and relative fault detection value (RFDV) of a measurable variable before a measured value exceeds its caution limit (CL) in order to detect faults in the initial stage. In addition, the daily trend (DT\%) of a measured value was calculated to investigate the increased amount percentage of this value per day after a period.

1. Relative alarm threshold (RAT): RAT is estimated as a critical threshold for any measurable variable that can be used in the indication of the probability of having a fault. According to the international standard IEC 60599 [13], the probability of having a failure may increase significantly at values much above typical concentration levels. The situation is then considered critical, for even though a fault may never occur at these high levels, the risk of having one is high. To calculate the RAT, three limits are required. The first limit is the caution limit (CL), that can be recorded from standard guidelines such as IEC 60599 [13], IEC 60422 [15], IEEE C57.106 [44], ASTM D3487 [45], CIGRE TB 771 [46], as well as limits reported by experimental investigations [2]. Selecting one of these standard guidelines is based on the organization's maintenance plan. Table 2 displays the CLs and standard guidelines used in the PSMD power plant. The second limit is the warning limit (WL), which was estimated here by supposing the starting of a fault's progression can occur when a measured value exceeds a typical value such as $50 \%$ of the caution limit (CL) value.

$$
\mathrm{WL}=\mathrm{CL} \times 0.50
$$


The third limit is alarm limit (AL) based on $80 \%$ of the CL. Estimation of $80 \%$ is based on an experimental investigation carried out by [47], which revealed that the relative error in the oil analytical method could be until $20 \%$ of the measured value. The sources of the error can be from oil sampling procedure, instrument inaccuracy, result deviation, human error, etc.

$$
\mathrm{AL}=\mathrm{CL} \times 0.80
$$

So, the relative alarm threshold (RAT) can be calculated based on the difference between AL and WL relative to WL (see Equation (3)).

$$
\mathrm{RAT}=(\mathrm{AL}-\mathrm{WL}) / \mathrm{WL}
$$

As seen in Table 2, the RAT value for any measurable variable was found to be 0.60 at different CLs.

Table 2. Relative Alarm Threshold (RAT) of measurable variables.

\begin{tabular}{ccccc}
\hline Measurable Variable (Oil Analysis) & CL & WL & AL & 120 \\
Rydrogen Gas & $150 \mathrm{ppm}^{1}$ & 75 & 16 & 0.6 \\
Acetylene Gas & $20 \mathrm{ppm}^{2}$ & 10 & 0.12 & 0.6 \\
Acidity & $0.150 \mathrm{mgKOH} / \mathrm{g}^{3}$ & 0.075 & 0.8 & 0.6 \\
Hydrogen Sulfide gas & $1 \mathrm{ppm}^{4}$ & 0.5 & 1.6 & 0.6 \\
Toluene & $2 \mathrm{ppm}^{5}$ & 1 & 0.6 \\
\hline
\end{tabular}

1,2 according to standard guideline IEC 60599 [13], ${ }^{3}$ according to standard guideline IEC 60422 for power transformer HV $\geq 170 \mathrm{kV}$ [15],

4,5 according to experimental investigation [2].

2. Relative fault detection value (RFDV): RFDV is calculated based on the difference between the first measured value $(w 1)$ of a measurable variable and WL relative to the WL, as demonstrated in Equation (4):

$$
\mathrm{RFDV}=(w 1-\mathrm{WL}) / \mathrm{WL}
$$

where $w 1$ is the first measured value of a measurable variable.

If the value of the RFDV < RAT (0.60), the transformer is still in a good condition. Whereas, if REDV $\geq 0.60$, that is an indication of the probability of having a fault. Hence, a new oil sample from the same transformer should be analyzed after a period, i.e., one month as recommended in [13] to record the second measured value (w2).

3. Daily trend (DT\%): DT is calculated according to the following equation:

$$
\text { Daily Trend, } \mathrm{DT} \%=((w 2-w 1) / w 1) \times 100) / \mathrm{n}_{\mathrm{d}}
$$

where $w 1$ is the first measured value, $w 2$ is the second measured value after a period, and $\mathrm{n}_{\mathrm{d}}$ is the number of days between $w 1$ and $w 2$.

If the DT $\geq 0.33 \%$, there is a strong indication of starting a fault in the transformer. Accordingly, it is recommended to immediately carry out a corrective action to prevent the progression of the fault to a risky level. The factor $0.33 \%$ is the critical percentage of increasing the rate of measured value per day according to the standard IEC 60599 [13], which considered the increase in the measured value more than $10 \%$ per one month $(\sim 0.33 \%$ per day) as an indication of an active fault. In contrast, if DT $<0.33 \%$ this is an indication of not having a significant trend in the measured values. Accordingly, the transformer can be considered still in a safe condition.

\subsection{Early Fault Diagnosis (EFD) Model-Concept and Verification}

The suggested early fault diagnosis (EFD) model is established to approach relevant cost-effective sustainable maintenance based on a fault trend chart that shows the faults' progression during the useful life of the transformers. This chart is created based on the 
outcome of the numerical method for early fault detection. In order to verify the outcome of the numerical method throughout the fault trend chart, four transformers with suspected failure propagation, of the PSMD power plant from the category "Start Fault" were selected based on covering all fault types to follow up their progression. The measurable variables that used in this chart were hydrogen gas, acetylene gas, acidity, hydrogen sulfide gas, and toluene to detect anticipated arcing, partial discharge, oxidation, and corrosion faults. The standard methods used for analysis of these measurable variables are demonstrated in Table 1. The uncertainty ( $\mathrm{U}_{\text {exp. }}$ ) of five repeated measurements of each measurable variable; hydrogen gas, acetylene gas, hydrogen sulfide gas, toluene, and acidity, was \pm 3.6 of mean value $104.4 \mathrm{ppm}, \pm 0.37$ of mean value $10.1 \mathrm{ppm}, \pm 0.035$ of mean value $0.51 \mathrm{ppm}$, \pm 0.063 of mean value $1.51 \mathrm{ppm}$, and \pm 0.031 of mean value $0.10 \mathrm{mgKOH} / \mathrm{g}$, respectively. Furthermore, the relative standard deviation (RSD\%) for same measurements was $3.2 \%$, $3.8 \%, 3.1 \%, 3.6 \%$ and $3,2 \%$, respectively. The historical data of these four transformers has been gathered since December 2018. Measured values for each transformer were recorded with three months interval, in March, June, September, and middle of November and December 2019 (see Figure 3).

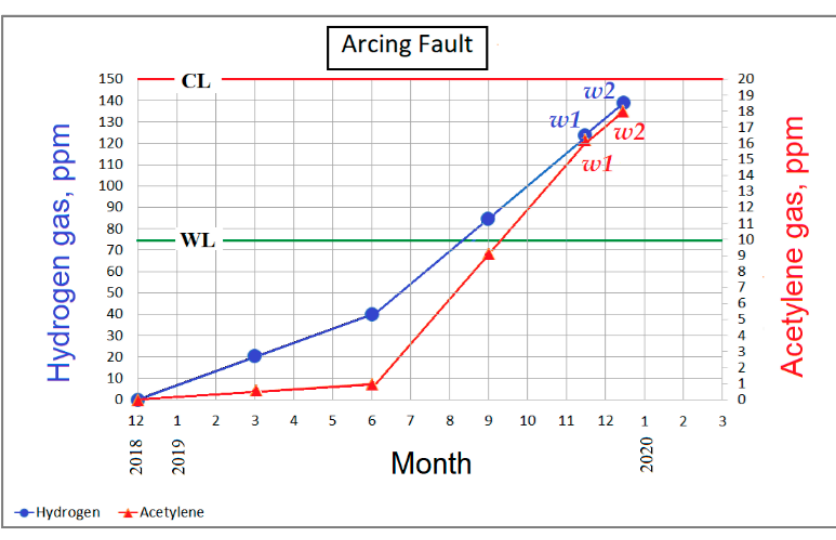

(a) First transformer

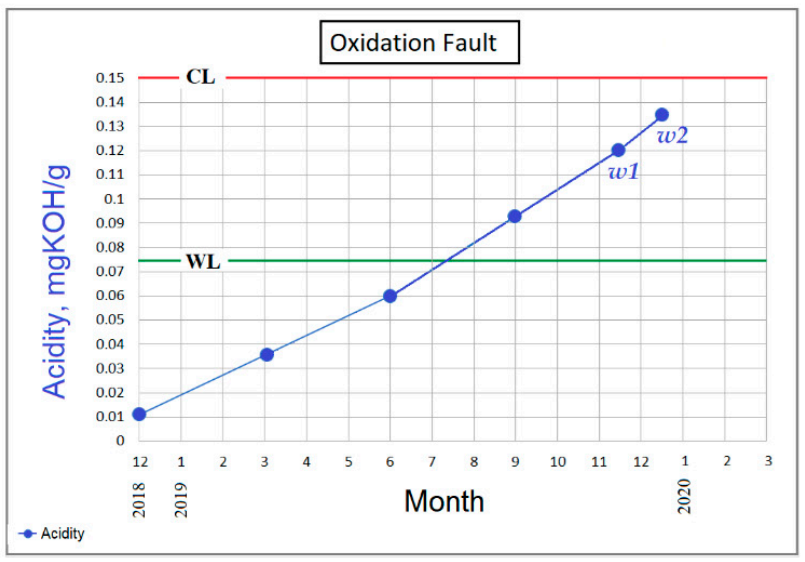

(c) Third transformer

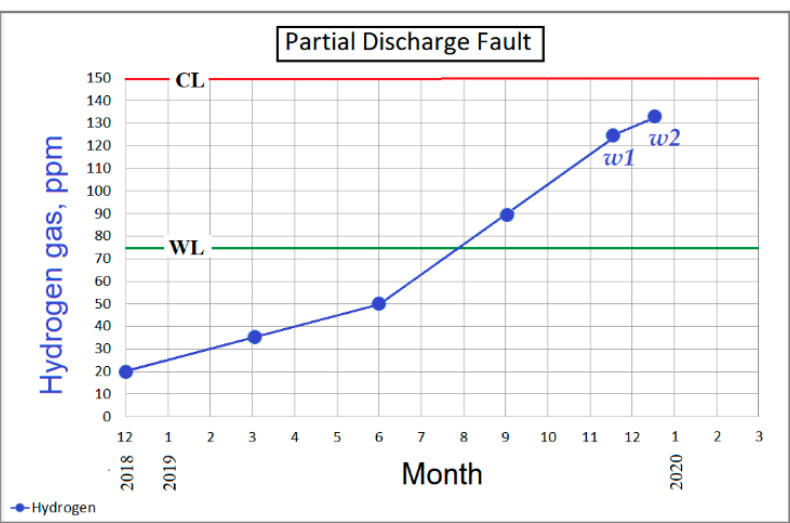

(b) Second transformer

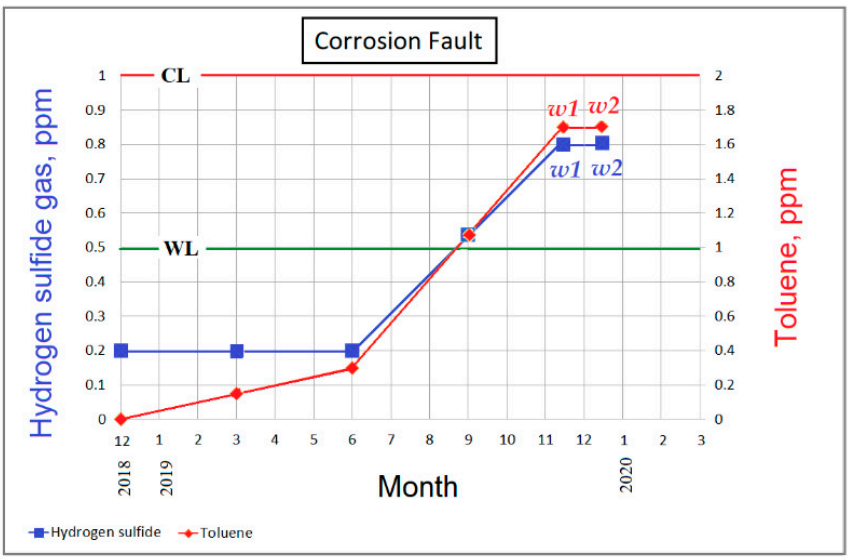

(d) Fourth transformer

Figure 3. Fault trend chart of the four transformers with suspected failure propagation. $C L=C$ Caution Limit; $W L=W a r n i n g$ Limit; $w 1$ = First measured value; $w 2$ = Second measured value. (a) Chart of "Arcing Fault" for the generation of the gases hydrogen and acetylene in the first transformer registered serial number 107772 (Power rate $=20 \mathrm{MVA}, \mathrm{HV}=33 \mathrm{kV}$ ); (b) Chart of "Partial Discharge Fault" for the generation of the hydrogen gas in the second transformer registered serial number 20081807 (30 MVA, $132 \mathrm{kV}$ ); (c) Chart of "Oxidation Deposits Fault" for the generation of the acidity in the third transformer registered serial number 3247PG1548 (300 MVA, 275 kV); (d) Chart of "Corrosion Deposits Fault" for the generation of the hydrogen sulfide gas and toluene compound in the fourth transformer registered serial number 07MD970101 (30 MVA, $132 \mathrm{kV}$ ). 


\section{Discussion}

The purpose of applying ABCD procedure in the PSMD power plant was to assess the sustainability level of the transformers and find the gaps to approach the vision of providing sustainable power with regard to minimized costs. The outcomes of this investigation can be summarized as follows:

1. The suggested early fault diagnosis (EFD) model using the fault trend chart, which shows the faults' progression based on the novel numerical method, was proved as a relevant model for approaching cost-effective sustainable maintenance. By utilizing this finding, the gaps to achieve the PSMD power plant vision were fulfilled, resulting in the extension of the lifetime of the four transformers with suspected failure propagation. A foremost challenge connected to this suggested model is the application on old transformers with insufficient historical data of oil analyses.

2. As seen in charts a-d of Figure 3, the measured values in March and June 2019 were less than warning limit (WL), which indicates that the transformers were in good condition. In September, the values exceeded the WL, but the calculated RFDV was $<0.60$, which indicates that the transformers were still in good condition. In November, the measured values $(w 1)$ for all transformers were significantly increased and accordingly the calculated RFDV was $>0.60$, which indicates the probability of having a fault in the initial stage. Hence, the analysis of the second measured values (w2) was carried out one month later, December 2019, to calculate the daily trend\% as follows:

- Figure 3a represents the generation of hydrogen and acetylene gases before exceeding the caution limits (CLs) of 150 and $20 \mathrm{ppm}$, respectively. The daily trend after one month was $>0.33 \%$, which indicates that the arcing fault is in progress. Accordingly, carrying out arcing measurement was recommended to find the source of overheating. In the arcing measurement, a high-frequency current transducer clamping on the transformer's grounding cable was used to detect the source and site of the arcing [48].

- Figure $3 b$ represents the generation of hydrogen gas before exceeding the CL of $150 \mathrm{ppm}$. The daily trend after one month was $<0.33 \%$, which indicates that the partial discharge fault is not in progress. However, if there is an indication of a partial discharge progression, the recommended corrective action could be to carry out a partial discharge test [49,50], utilizing infrared thermal imaging technology [51] to find the source of overheating and the site of the expected flashpoint in the transformer.

- Figure 3c represents the formation of acidity before exceeding the CL of $0.15 \mathrm{mgKOH} / \mathrm{g}$. The daily trend after one month was $>0.33 \%$, which indicates that the oxidation fault is in progress. Accordingly, adding an antioxidant additive in the insulating oil was recommended to suppress the oxidation reaction [52].

- Figure $3 \mathrm{~d}$ represents the generation of hydrogen sulfide gas and toluene compound before exceeding the CLs of 1 and $2 \mathrm{ppm}$, respectively. The daily trend after one month was $<0.33 \%$, which indicates that the corrosion fault is not in progress. However, if there is an indication of a corrosion progression, the recommended corrective action could be adding an anticorrosion additive in the insulating oil to suppress the corrosion reaction [53].

3. An example of applying the numerical method is demonstrated here to elucidate the calculation process. Suppose a maintenance team in a power plant observed a variation in the transformer performances when the measured value of hydrogen gas, a key indicator of partial discharge, was high. An oil sample from this transformer was analyzed for the first measured value of hydrogen gas $(w 1)$ and was found $125 \mathrm{ppm}$. The question: Is there any indication of partial discharge fault in progress? 
As the measured value of the hydrogen was $125 \mathrm{ppm}$ in the example, which is below caution limit $(\mathrm{CL}=150 \mathrm{ppm})$ but above the alarm limit $(\mathrm{AL}=120 \mathrm{ppm})$ (see Table 2), the relative fault detection value (RFDV) of hydrogen gas value should be calculated according to Equation (4),

$$
\mathrm{RFDV}=(w 1-\mathrm{WL}) / \mathrm{WL}=(125-75) / 75=0.67
$$

The REDV was $>$ RAT (0.60), so it was recommended to take another oil sample after one month (30 days) for analysis of the second measured value ( $w 2)$. The value of $w 2$ was found $138 \mathrm{ppm}$. Then the daily trend should be calculated according to Equation (5),

$$
\left.\mathrm{DT}=((w 2-w 1) / w 1) * 100) / \mathrm{n}_{\mathrm{d}}=((138-125) / 125) * 100\right) / 30=0.35 \%
$$

As the DT of hydrogen gas value was $>0.33 \%$, there is a strong indication of starting a partial discharge fault. Accordingly, it is recommended to start an investigation to solve the problem before fault's progression to a risky level. This example shows that the corrective action could be carried out before a measured value exceeds its caution limit. The flow diagram in Figure 4 elucidates the process steps of using the numerical method in the maintenance strategy.

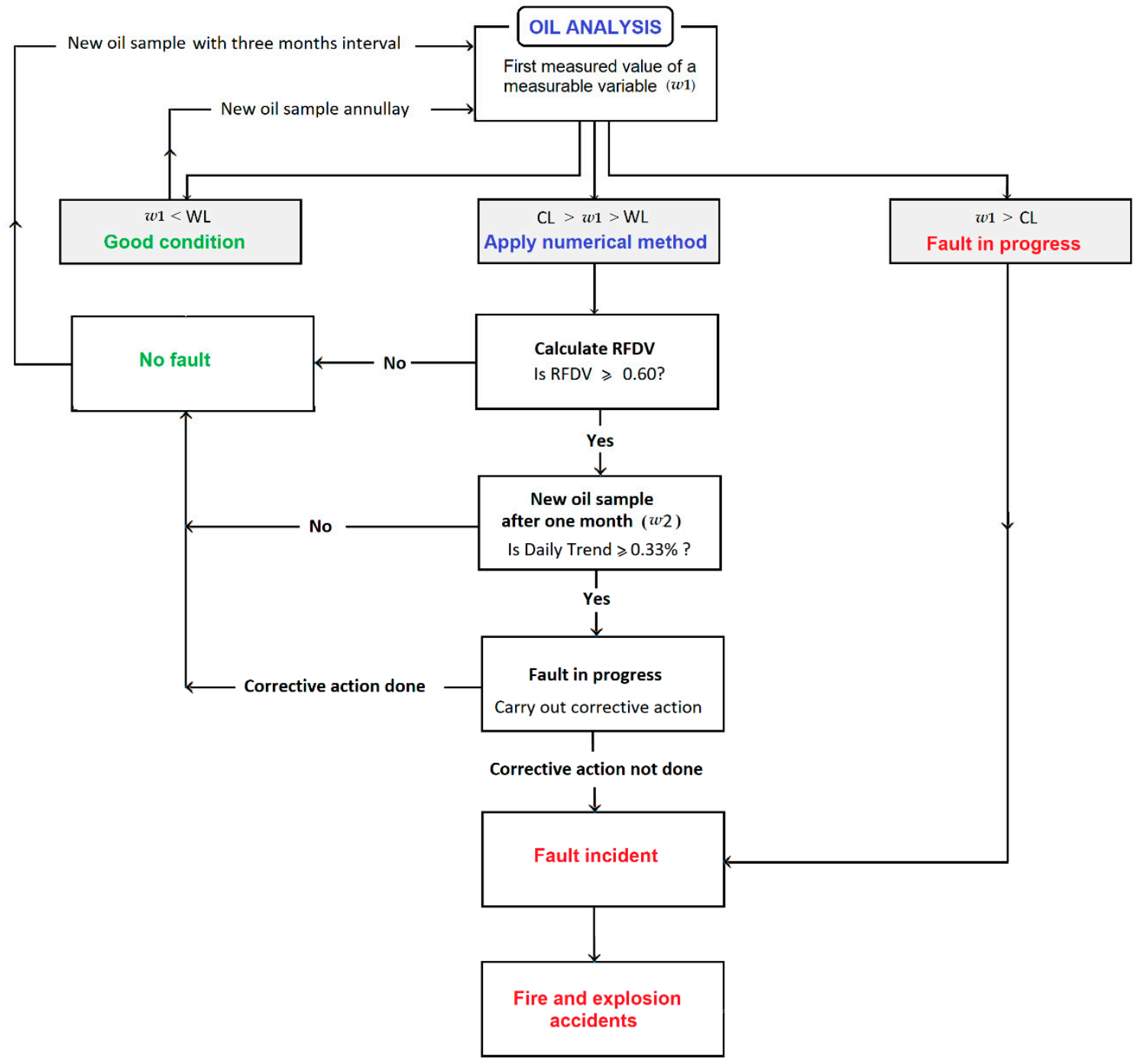

Figure 4. Flow diagram of the numerical method. $w 1=$ First measured value, $w 2=$ Second measured value $C L=C a u t i o n$ Limit, WL = Warning Limit, and RFDV = Relative Fault Detection Value. 
The flow diagram starts with oil analysis of the first measured value (w1) representing any related measurable variable. There are three alternative evaluation outcomes for the $w 1$. The first is $w 1$ less than $\mathrm{WL}$, which reveals good condition of the transformer, hence a new oil sample could be recommended annually according to [15] or according to the organization maintenance plan. The second is $w 1$ more than CL, which indicates a fault in progress, i.e., fault has already occurred and may lead to fire and explosion accidents. The last is $w 1$ more than WL and below CL, which reveals the probability of having a fault in the initial stage. In this last alternative, the numerical method could be applied to assess the fault level and carry out appropriate corrective action to prevent fault incidence. If the fault is not in the risky level, the oil sample could be recommended for analysis with three months interval according to [2], in order to gather sufficient data for an accurate evaluation of the fault's progression. The generic procedure described in Figure 4 provides a structured process for CBM purposes using any measurable variable at any caution limit. The main advantage of applying the numerical method is the possibility of early faults detection before progression to a risky level. The disadvantage is the requirement of historical data to track the fault level.

4. By applying the fault trend chart using the numerical method, the faults were detected early before progression to a risky level, resulting in the extension of the lifetime of the transformers with suspected failure propagation. Hence, the gap in the implementation of sustainable maintenance is fulfilled.

5. The outline of capabilities and shortcomings in the early fault diagnosis (EFD) model comparing with other technical methods of sustainable maintenance are demonstrated in a matrix schedule (see Table 3).

Table 3. Matrix of capabilities and shortcomings in the technical methods of sustainable maintenance.

\begin{tabular}{ccccc}
\hline Methods of Sustainable Maintenance & Efficiency & Cost Investment & Ease of Apply & Limitation \\
\hline Energy-efficient green transformers & Good & High & No & Only for new transformers \\
Natural ester oil & Good & High & No & Low electrical resistivity \\
Waste oil recycle & Good & High & No & High investment cost \\
Early Diagnosis Method (EFD) Model & Good & Low & Yes & Needs historical data \\
\hline
\end{tabular}

6. For further verification and validation, the model will be applied for tracking the fault type "copper corrosion" on 84 transformers at the PSMD power plant. For future work, the application of the EFD model can be extended to another field, such as any asset containing oil in production manufacturing. Future work could also involve investigations to find a solution to the insufficient historical oil analysis data of transformers to be used in the EFD model.

\section{Conclusions}

The principal conclusion of this paper is the importance of viewing the maintenance strategy of transformers from a strategic sustainability perspective, in order to approach relevant cost-effective sustainable maintenance. This was proven in the empirical study by detecting the faults in the initial stage using the early fault diagnosis (EFD) model. Several conclusions can also be highlighted as follows:

- The suitability of applying the $\mathrm{ABCD}$ procedure to assess the sustainability aspects for moving toward sustainable maintenance. Due to its intelligible guidance structure and its flexible process, the $\mathrm{ABCD}$ procedure is a useful and well-organized tool for integrating sustainability into transformer maintenance, which was demonstrated by the empirical study.

- $\quad$ The suggested EFD model for the empirical study has succeeded in filling the gap to approach relevant cost-effective sustainable maintenance. 
- The importance of defining the correct time of carrying out corrective actions before the measured value of a measurable variable exceeds its caution limit. This was illustrated throughout tracking the faults in the fault trend chart.

- The benefits of integrating the EFD model in the CBM strategy compared with other models detecting faults in the initial stage, defining the correct time of corrective actions, easily modelling any measurable variable in the fault trend chart at any caution limit, and providing a transformer diagnosis at specific and overall fault parameters.

Author Contributions: Conceptualization, visualization, investigation, methodology, writingoriginal draft preparation, R.J.; supervision, reviewing and editing of the maintenance part, M.K.; reviewing and editing of the sustainability part, J.S.; providing data, participating in the workshops, and reviewing the outcome of the workshops, M.A. (Mohammed Alhattab), M.A. (May Alhendi), and A.B. All authors have read and agreed to the published version of the manuscript.

Funding: This research received no external funding.

Institutional Review Board Statement: Not applicable.

Informed Consent Statement: Not applicable.

Data Availability Statement: Not applicable.

Acknowledgments: Authors acknowledge the support of the PSMD-power plant, Kuwait Ministry of Electricity and Water, for providing the analysis data and resources. Authors also wish to acknowledge the support of SAECO laboratory of Saudi Arabian Engineering Company for analysis service.

Conflicts of Interest: The authors declare no conflict of interest. The funders had no role in the design of the study; in the collection, analyses, or interpretation of data; in the writing of the manuscript, or in the decision to publish the results.

\section{Abbreviations}

$\begin{array}{ll}\text { AL } & \text { Alarm Limit } \\ \text { BTA } & \text { Benzo Triazole } \\ \text { CBM } & \text { Condition Based Maintenance } \\ \text { CCD } & \text { Covered Conductor Deposition } \\ \text { CL } & \text { Caution Limit } \\ \text { CM } & \text { Condition Monitoring } \\ \text { DBDS } & \text { Dibenzyl disulfide } \\ \text { DT } & \text { Daily Trend \% } \\ \text { EFD } & \text { Early Fault Diagnosis } \\ \text { FSSD } & \text { Framework for Strategic Sustainable Development } \\ \text { HI } & \text { Health Index \% } \\ \mathrm{H}_{2} \text { S } & \text { Hydrogen sulfide gas } \\ \text { Irgamet 39 } & \text { Toluiltriazole-dialkylamine } \\ \text { MPM } & \text { Markov Prediction Model } \\ \text { PCB } & \text { Polychlorinated biphenyl } \\ \text { PPM } & \text { Part per million } \\ \text { PSMD } & \text { Primary Substation Maintenance Department } \\ \text { RAT } & \text { Relative Alarm Threshold } \\ \text { RFDV } & \text { Relative Fault Detection Value } \\ \text { RSD } & \text { Relative Standard Deviation \% } \\ \text { SDM } & \text { Statistical Distribution Model } \\ \text { Uexp } & \text { Expanded uncertainty } \\ \text { WL } & \text { Warning Limit }\end{array}$




\section{References}

1. Kulkarni, S.; Khaparde, S. Transformer Engineering Design and Practice, 1st ed.; Marcel Dekker: New York, NY, USA, 2004.

2. Jadim, R.; Kans, M.; Rehman, S.; Alhems, L.A. A relevant condition monitoring of corrosive sulphur deposition on the windings of oil-filled electrical transformers. IEEE Trans. Dielectr. Electr. Insul. 2020, 27, 1736-1742. [CrossRef]

3. Jadim, R.; Ingwald, A.; Al-Najjar, B. A Review Study of Condition Monitoring and Maintenance Approaches for Diagnosis Corrosive Sulphur Deposition in Oil-Filled Electrical Transformers. In Proceedings of the New Paradigm of Industry 4.0, Studies in Big Data 64, Bhubaneswar, India, 27 September 2018.

4. Akshatha, A.; Anjana, K.; Ravindra, D.; Vishwanath, G.; Rajan, J. Study of Copper Corrosion in Transformers due to Sulphur in Oil Using Chemical Methods. In Proceedings of the International Conference IEEE on Electrical Insulation and Dielectric Phenomena (CEIDP), Montreal, QC, Canada, 14 October 2012.

5. Liland, K.; Kes, M.; Glomm, M.; Lundgaard, L.; Christensen, B. Study of oxidation and hydrolysis of oil impregnated paper insulation for transformers using a microcalorimeter. IEEE Trans. Dielectr. Electr. Insul. 2011, 18, 2059-2068. [CrossRef]

6. El-Harbawi, M.; Al-Mubaddel, F. Risk of fire and explosion in electrical substations due to the formation of flammable mixtures. Sci. Rep. Nat. Res. 2020, 10, 6295. [CrossRef] [PubMed]

7. Allan, J. Fires and Explosions in Substations. In Proceedings of the International Conference and Exhibition IEEE/PES on Transmission and Distribution, Yokohama, Japan, 6 October 2002.

8. Vahidi, F.; Tenbohlen, S. Statistical Failure Analysis of European Substation Transformers. In Proceedings of the Conference ETG-Fachbericht—Diagnostik Elektrischer Betriebsmittel, Berline, Germany, 25 November 2014.

9. Heinz-Peter, B.; Nicole, F. Reliability and vulnerability of transformers for electricity transmission and distribution. J. Pol. Saf. Reliab. 2015, 3, 15-23.

10. Amaro, P.S.; Facciotti, M.; Holt, A.F.; Pilgrim, J.A.; Lewin, P.L.; Brown, R.C.D.; Wilson, G.; Jarman, P. Tracking Copper Sulfide Formation in Corrosive Transformer Oil. In Proceedings of the Annual Report Conference on Electrical Insulation and Dielectric Phenomena: Proceedings of the IEEE Conference, Chenzhen, China, 20 October 2013.

11. Yahaya, M.S.; Azis, N.; Selva, A.M.; Ab Kadir, M.Z.A.; Jasni, J.; Hairi, M.H.; Ghazali, Y.Z.Y.; Talib, M.A. Effect of pre-determined maintenance repair rates on the health index state distribution and performance condition curve based on the Markov prediction model for sustainable transformers asset management strategies. Sustainability 2018, 10, 3399. [CrossRef]

12. EN 13306. Standard for Maintenance-Maintenance Terminology. Available online: https://infostore.saiglobal.com/en-gb/ Standards/BS-EN-13306-2017-232245_SAIG_BSI_BSI_543804/ (accessed on 1 January 2017).

13. IEC 60599, Mineral Oil-Filled Electrical Equipment in Service-Guidance on the Interpretation of Dissolved and Free Gases Analysis. In Proceedings of the International Electrotechnical Commission, Geneva, Switzerland, 16 September 2015.

14. Wada, J.; Ueta, G.; Okabe, S. Method to evaluate the degradation condition of transformer insulating oil—establishment of the evaluation method and application to field transformer oil. IEEE Trans. Dielectr. Electr. Insul. 2015, 22, 1266-1274. [CrossRef]

15. IEC 60422. Mineral Insulating Oils in Electrical Equipment-Supervision and Maintenance Guidance. In Proceedings of the International Electrotechnical Commission, Geneva, Switzerland, 10 January 2013.

16. Bustamante, S.; Manana, M.; Arroyo, A.; Castro, P.; Laso, A.; Martinez, R. Dissolved gas analysis equipment for online monitoring of transformer oil: A review. Sensors 2019, 19, 4057. [CrossRef]

17. Mharakurwa, E.T.; Nyakoe, G.N.; Akumu, A.O. Power transformer fault severity estimation based on dissolved gas analysis and energy of fault formation technique. J. Electr. Comput. Eng. 2019, 2019, 1-10. [CrossRef]

18. Mendler, R.; Osborne, G.D.; Thevenet, T.; Janak, M. Electrical Equipment Maintenance 101. In Proceedings of the IEEE Petroleum and Chemical Industry Conference (PCIC), Toronto, ON, Canada, 19 September 2011.

19. Mohd Selva, A.; Azis, N.; Shariffudin, N.S.; Ab Kadir, M.Z.A.; Jasni, J.; Yahaya, M.S.; Talib, M.A. Application of statistical distribution models to predict health index for condition-based management of transformers. Appl. Sci. 2021, 11, 2728. [CrossRef]

20. Mohd Selva, A.; Azis, N.; Yahaya, M.S.; Ab Kadir, M.Z.A.; Jasni, J.; Yang Ghazali, Y.Z.; Talib, M.A. Application of Markov model to estimate individual condition parameters for transformers. Energies 2018, 11, 2114. [CrossRef]

21. Liang, Z.; Parlikad, A. A Markovian model for power transformer maintenance. Electr. Power Energy Syst. 2018, 99, 175-182. [CrossRef]

22. Jasiulewicz-Kaczmarek, M. The Role and Contribution of Maintenance in Sustainable Manufacturing. In Proceedings of the International Conference 7th IFAC on Manufacturing Modelling, Management, and Control, International Federation of Automatic Control, Saint Petersburg, Russia, 19 June 2013.

23. Hjortha, P.; Bagheria, A. Navigating towards sustainable development: A system dynamics approach. Futures 2006, $38,74-92$. [CrossRef]

24. Vladimir, V.; Jasiulewicz-Kaczmarek, M. Maintenance in sustainable manufacturing. Sci. J. Logist. 2014, 10, $273-284$.

25. Yurekten, S.; Kara, A.; Mardikyan, K. Energy Efficient Green Transformer Manufacturing with Amorphous Cores. In Proceedings of the International Conference on Renewable Energy Research and Applications, Madrid, Spain, 20 October 2013.

26. Saettaa, S.; Caldarellia, V. Lean production as a tool for green production: The green foundry case Study. ScienceDirect 2020, 42 , 498-502. [CrossRef] 
27. Pompili, M.; Calcara, L.; Sturchio, A.; Catanzaro, F. Natural Esters Distribution Transformers: A Solution for Environmental and Fire Risk Prevention. In Proceedings of the IEEE International Conference, Annual Conference (AEIT), Capri, Italy, 5 October 2016.

28. Perrier, C.; Ryadi, M.; Bertrand, Y.; Tran Du, C. Comparison between Mineral and Ester Oils. In Proceedings of the Cigre 10 Conference, Paris, France, 22 August 2010.

29. Hernandez-Herrera, H.; Silva-Ortega, J.I.; Mejia-Taboada, M.; Jacome, A.D.; Torregroza-Rosas, M. Natural Ester Fluids Applications in Transformers as a Sustainable Dielectric and Coolant. In Proceedings of the AIP Proceeding Conference 2123, Beirut, Lebanon, 10 April 2019.

30. Liu, Q.; Venkatasubramanian, R.; Matharage, S.; Wang, Z. Effect of oil regeneration on improving paper conditions in a distribution transformer. Energy 2019, 12, 1665. [CrossRef]

31. Choi, H.; Veriansyah, B.; Kim, J.; Duck, K.J.; Lee, Y. Recycling of transformer oil contaminated by polychlorinated biphenyls (PCBs) using catalytic hydrodechlorination. J. Environ. Sci. Health Part A 2009, 44, 494-501. [CrossRef]

32. Schulte, J.; Hallstedt, S. Workshop Method for Early Sustainable Product Development. In Proceedings of the International Design Conference-DESIGN, Dubrovnik, Croatia, 21 May 2018.

33. Robèrt, K.; Broman, G.; Waldron, D.; Ny, H.; Hallstedt, S.; Cook, D.; Johansson, L.; Oldmark, J.; Basile, G.; Haraldsson, H.; et al. Planning and acting strategically towards sustainability. In Sustainability Handbook, 2nd ed.; Studentlitteratur AB: Lund, Sweden, 2019.

34. Broman, G.; Robèrt, K. A framework for strategic sustainable development. J. Clean. Prod. 2017, 140, 17-31. [CrossRef]

35. Yin, R.K. Case Study Research and Applications: Design and Methods, 6th ed.; SAGE Publications: Thousand Oaks, CA, USA, 2018.

36. Filippis, C.; Maiber, I.; Vidler, H.; Wilbrink, T. Taking Care to Change Trajectory-Exploring an Integrated Process of Collective Narrative Practices and Strategic Sustainable Development. Master's Thesis, Blekinge Institute of Technology Karlskrona, Blekinge, Sweden, 2019.

37. Schulte, J.; Hallstedt, S. Company risk management in light of the sustainability transition. Sustainability 2018, 10, 4137. [CrossRef]

38. Robert, K. Tools and concepts for sustainable development, how do they relate to a general framework for sustainable development, and to each other? J. Clean. Prod. 2000, 8, 243-254. [CrossRef]

39. Schulte, J.; Villamil, C.; Hallstedt, S.I. Strategic sustainability risk management in product development companies: Key aspects and conceptual approach. Sustainability 2020, 12, 10531. [CrossRef]

40. IEC 60567. Oil-Filled Electrical Equipment—Sampling of Gases and of Oil for Analysis of Free and Dissolved Gases—Guidance. In Proceedings of the International Electrotechnical Commission, Geneva, Switzerland, 4 June 2013.

41. IEC 62021-3. Insulating Liquids-Determination of Acidity-Part 3: Test Methods for Non-Mineral Insulating Oils. In Proceedings of the International Electrotechnical Commission, Geneva, Switzerland, 19 March 2014.

42. ASTM D5504. Standard Test Method for Determination of Sulfur Compounds in Natural Gas and Gaseous Fuels by Gas Chromatography and Chemiluminescence. In Proceedings of the American Society for Testing and Materials, West Conshohocken, PA, USA, 1 November 2020.

43. ASTM D5580. Standard Test Method for Determination of Benzene, Toluene, Ethylbenzene, $\mathrm{p} / \mathrm{m}-\mathrm{Xylene,} \mathrm{o-Xylene,} \mathrm{C9} \mathrm{and}$ Heavier Aromatics, and Total Aromatics in Finished Gasoline by Gas Chromatography. In Proceedings of the American Society for Testing and Materials, West Conshohocken, PA, USA, 1 April 2021.

44. C57.106. IEEE Guide for Acceptance and Maintenance of Insulating Mineral Oil in Electrical Equipment; The Institute of Electrical and Electronics Engineers: New York, NY, USA, 5 December 2015.

45. ASTM D3487. Standard Specification for Mineral Insulating Oil Used in Electrical Apparatus; American Society for Testing and Materials: West Conshohocken, PA, USA, 15 June 2016.

46. CIGRE TB 771. Advances in DGA Interpretation. Available online: https://e-cigre.org/publication/771-advances-in-dgainterpretation (accessed on 1 July 2019).

47. Arrhenius, K.; Fischer, A.; Buker, O.; Adrien, H.; El Masri, A.; Lestremaub, F.; Robinsonc, T. Analytical methods for the determination of oil carryover from CNG/biomethane refueling stations recovered in a solvent. R. Soc. Chem. 2020, 10, 11907-11917. [CrossRef]

48. Seo, J.; Ma, H.; Saha, T. A Joint vibration and arcing measurement system for online condition monitoring of onload tap changer of the power transformer. IEEE Trans. Power Deliv. 2017, 32, 1031-1038. [CrossRef]

49. Stone, C. Partial discharge diagnostics and electrical equipment insulation condition assessment. IEEE J. Mag. 2005, 5, 891-904. [CrossRef]

50. IEC 60270. Consolidated Version High-Voltage Test Strategy_Partial Discharge Measurements. In Proceedings of the International Electrotechnical Commission, Geneva, Switzerland, 27 November 2015.

51. Qingsong, C.; Yongxiang, L.; Zhixiang, L.; Zhenyu, Z.; Shen, Z.; Zhiyuan, W. Analysis of Transformer Abnormal Heating Based on Infrared Thermal Imaging Technology. In Proceedings of the 2nd IEEE Conference on Energy Internet and Energy System Integration, Beijing, China, 20 October 2018. 
52. Yehye, W.; Abdul Rahman, N.; Ariffin, A.; Abd Hamid, S.B.; Alhadi, A.; Kadir, F.; Yaeghoobi, M. Understanding the chemistry behind the antioxidant activities of butylated hydroxytoluene (BHT): A review. Eur. J. Med. Chem. 2015, 101, 295-312. [CrossRef] [PubMed]

53. Rehman, S.; Alhems, L.; Jadim, R.; Al Faraj, B.; Balasubramanian, K.; Al Mutairi, K.; Al-Yemni, A.; Shinde, D.; Al-Hsaien, S Maximum acceptable concentrations of dbds, sulphur mercaptan and optimal concentration of metal deactivators for safe and prolonged operation of power transformers. IEEE Trans. Dielectr. Electr. Insul. 2016, 4, 2438-2442. [CrossRef] 